Ciência Florestal, Santa Maria, v. 22, n. 4, p. 655-668, out.-dez., 2012

ISSN 0103-9954

\title{
FLORÍSTICA E ANÁLISE DE SIMILARIDADE DE ESPÉCIES ARBÓREAS DA MATA DA PRAIA DO TOTÓ, PELOTAS, RS, BRASIL
}

\author{
FLORISTIC AND SIMILARITY ANALYSIS OF TREE SPECIES IN “MATA DA PRAIA DO TOTÓ’, \\ PELOTAS, RIO GRANDE DO SUL STATE, BRAZIL
}

\author{
Tiago Schuch Venzke ${ }^{1}$ Rogério Soares Ferrer ${ }^{2}$ Maria Antonieta Décio da Costa ${ }^{3}$
}

\section{RESUMO}

O levantamento florístico de espécies arbóreas foi realizado em uma mata de restinga no município de Pelotas, Rio Grande do Sul, Brasil. O local de estudo é conhecido como Mata da Praia do Totó e compreende um remanescente formado por ambientes de matas de restinga arenosa e turfosa. Foi amostrado um total de 65 espécies nativas compreendendo 51 gêneros distribuídos em 34 famílias.A família que apresentou o maior número de espécies foi Myrtaceae com dez espécies, seguida de Salicaceae e Rubiaceae. Os gêneros mais representativos foram Myrsine e Eugenia, respectivamente com quatro e três espécies. A análise de similaridade amostrou que a mata arenosa é floristicamente relacionada com florestas ciliares e de encosta e a mata turfosa com outras florestas localizadas em áreas de saturação hídrica permanente do solo. A riqueza de espécies do local é elevada para matas de restinga no Rio Grande do Sul, provavelmente pela influência de florestas situadas na Serra dos Tapes e pela diversidade de ambientes que compõem a área de estudo.

Palavras-chave: Praia do Laranjal; Laguna dos Patos; ecossistemas costeiros; mata de restinga.

\begin{abstract}
The floristic survey of tree species was performed in a 'Restinga' forest, municipality of Pelotas, Rio Grande do sul State, Brazil. The area studied is known as 'Mata da Praia do Totó'('Totó' beach forest), and comprises a remnant formed by a sandy and turf 'Restinga' forest. A total 65 native species were sampled comprising 51 genera distributed in 34 families. The family with the greatest number of species was Myrtaceae, with ten species, followed by Salicaceae and Rubiaceae. The most representative genera were Myrsine and Eugenia, respectivelly sampled with four and three species. The analysis of similarity sampled that the sandy forest is floristically related to riparian and hillside forests and the forest peat is related to other forests located in areas of permanent water saturation of soil. Species richness of the site is high for 'Restinga' forests in Rio Grande do Sul state, probably due to the influence of forests located in Serra dos Tapes and by diversity of the environments that make up the study area.
\end{abstract}

Keywords: 'Laranjal' beach, 'Patos' lagoon; coastal ecosystems; 'Restinga' area.

1. Bacharel em Ecologia, Esp., Mestrando do Programa de Pós-Graduação em Botânica, Universidade Federal de Viçosa, Av. Peter Henry Rolfs, s/n, CEP 36570-000, Viçosa (MG). Bolsista CNPq. tiago.venzke@ufv.br / venzke.tiago@gmail.com

2. Engenheiro Agrônomo, M.Sc., Professor, Laboratório de Botânica, Universidade Católica de Pelotas, Rua Félix da Cunha, 412, CEP 96010-000, Pelotas (RS). taguatha@hotmail.com

3. Bióloga, Dra., Professora Adjunta, Laboratório de Botânica, Universidade Católica de Pelotas, Rua Félix da Cunha, 412, CEP 96010-000, Pelotas (RS). antonietacosta@hotmail.com

Recebido para publicação em 19/05/2009 e aceito em 12/08/2011 


\section{INTRODUÇÃO}

O conhecimento da distribuição geográfica dos elementos da flora que integram os ecossistemas da paisagem é de relevante importância para planejamento e gestão dos recursos naturais. Assim, levantamentos florísticos em remanescentes naturais são necessários a fim de verificar a composição em espécies da vegetação e determinar áreas prioritárias para conservação e uso sustentável dos recursos naturais.

Aregião geomorfológica da planície costeira tem formação recente do ponto de vista geológico. O desenvolvimento dessa planície sedimentar é decorrente de transgressões e regressões marinhas, que são movimentos de avanço e recuo das águas do mar com relação ao continente (ARAÚJO e LACERDA, 1987; TOMAZZELLI et al., 2000; STRECK et al., 2008). A sua estrutura geológica atual é representada por amplo depósito de natureza marinha e continental (VIEIRA e RANGEL, 1988), que foi modelada em decorrência de deposições de areia, tempestades, correntes marinhas e ventos, resultando uma topografia complexa e diversificada (ARAÚJO e LACERDA, 1987). No Brasil, essa dinâmica de formação da planície costeira com as respectivas vegetações, representa um ecossistema muito diversificado em fisionomia, florística e estrutura (ASSIS et al., 2004). A ampla variabilidade geomorfológica da região determina um mosaico vegetacional complexo variando deste os tipos herbáceos até os arbustivos e os arbóreos, sendo todo o conjunto denominado de "Complexo de Restinga" (RIZZINI, 1997).

As comunidades florestais que colonizam as restingas no estado do Rio Grande do Sul apresentam-se sob a configuração de matas ciliares e matas insulares. Essas matas insulares são denominadas de capões e estão associadas a depósitos arenosos ou turfáceos. Elas mostram o exemplo da vegetação mais complexa ou em fase avançada da sucessão ecológica para a Planície Costeira (WAECHTER, 1985; TEIXEIRA et al., 1986). A abordagem de Waechter (1990) estabelece uma divisão da unidade fitogeográfica da restinga no Rio Grande do Sul em quatro comunidades arbóreas básicas: comunidades savânicas (palmares ou butiazais), matas ciliares, matas arenosas e matas turfosas.

Os estudos nestas comunidades florestais, em sua maioria, foram desenvolvidos na porção norte da Laguna dos Patos (DILLENBURG et al., 1992; ROSSONI, 1993; WAECHTER et al., 2000; MORAES e MONDIN, 2001; KINDEL, 2002; SCHERER et al., 2005). Em outras áreas do entorno do complexo lagunar Patos-Mirim foram localizados os trabalhos de Kilca (2002) e De Marchi (2005) que analisaram a florística e a estrutura de florestas situadas em mata ciliares. Dorneles e Waechter (2004a); Dorneles e Waechter (2004b) estudaram a estrutura de matas de restinga turfosa e arenosa na parte central da Laguna no Parque Nacional da Lagoa do Peixe. Porto e Dillenburg (1986) e Waechter e Jarenkow (1998) realizaram respectivamente estudos florístico e fitossociológico na porção sul, na Estação Ecológica do Taim (ESEC-Taim).

A área deste estudo é conhecida popularmente como Mata da Praia do Totó e representa um remanescente de área contínua de mata de restinga com tamanho apreciável na porção sul da Laguna dos Patos. No município de Pelotas, as matas de restinga são encontradas atualmente na forma de pequenos remanescentes colonizando a parte superior e a inferior das barreiras holocênicas, bem como depressões, dunas e falésias interioranas à Laguna dos Patos.

Assim foi realizado o levantamento florístico das espécies arbóreas de uma mata de restinga no município de Pelotas, RS, com o objetivo de conhecer a riqueza desta comunidade vegetal e suas relações florísticas com outras florestas nativas, incrementando o conhecimento da distribuição geográfica e ecológica da flora arbórea na Planície Costeira do Rio Grande do Sul.

\section{MATERIAL E MÉTODO}

\section{Caracterização do local}

O remanescente de Mata de Restinga localiza-se na Praia do Laranjal, município de Pelotas, Rio Grande do Sul, (Figura 1), sendo conhecido popularmente como "Mata da Praia do Totó" (31 43 '25"'S e 52 $11^{\circ}$ '46"W, altitude < $10 \mathrm{~m}$ ). A área situa-se, segundo a classificação proposta por Teixeira et al., (1986), na região fitogeográfica pertencente a Áreas de Formação Pioneira com Influência Fluvial. A mata está localizada na abrangência das condições dinâmicas do estuário da Laguna dos Patos e afastada aproximadamente $48 \mathrm{~km}$ do oceano. Possui cerca de $6.200 \mathrm{~m}$ de comprimento, largura média de $266 \mathrm{~m}$ e aproximadamente 160 ha de área total, cuja configuração alongada estende-se paralela à margem da Laguna dos Patos. O local é 
protegido ambientalmente pela legislação municipal que declara de valor paisagístico e ecológico a Mata da Praia do Totó (PELOTAS, 1998).

Conforme a classificação climática do sistema de Koeppen, a Planície Litorânea enquadrase no tipo "Cfa", ou clima subtropical úmido. No município de Pelotas foi registrada a temperatura média anual de $17,5^{\circ} \mathrm{C}$, sendo as médias mensais de $23,0{ }^{\circ} \mathrm{C}$ e $11,9^{\circ} \mathrm{C}$ para o mês mais quente e para o mês mais frio, respectivamente (OLIVEIRA e RIBEIRO, 1986).

\section{Metodologia de estudo}

O levantamento florístico efetuou-se pelo método de caminhamento na área do estudo. As espécies foram coletadas e/ou observadas no interior e bordas da mata, assim como árvores e capões isolados na paisagem, tanto nos ambientes arenosos como nos turfosos. Outras áreas de mata de restinga no município de Pelotas foram visitadas durante o levantamento: uma na Praia do Laranjal denominada de Vila Mariana (31 45 '21's e $\left.52^{\circ} 14^{\prime} 16^{\prime \prime} \mathrm{W}\right)$ e os capões do Pontal da Barra ( $31^{\circ} 46^{\prime} 34^{\prime \prime}$ 'S e $\left.52^{\circ} 14^{\prime} 09^{\prime \prime} \mathrm{W}\right)$.

A coleta dos dados focou-se nas espécies com indivíduos de diâmetro a altura do peito (DAP) de no mínimo $5 \mathrm{~cm}$ e altura mínima de $4 \mathrm{~m}$. A identificação das espécies foi realizada por consulta a especialistas, por meio do conhecimento popular e determinada através de literatura especializada. As espécies foram classificadas nas famílias reconhecidas pelo Angiosperm Phylogeny Group III - APG III (2009). A nomenclatura das espécies seguiu Sobral et al., (2006). O material botânico com partes férteis (flores e/ou frutos) foi coletado e processado conforme as recomendações de Fidalgo e Bononi (1984) e anexado ao acervo do Herbário PEL da Universidade Federal de Pelotas (UFPEL).

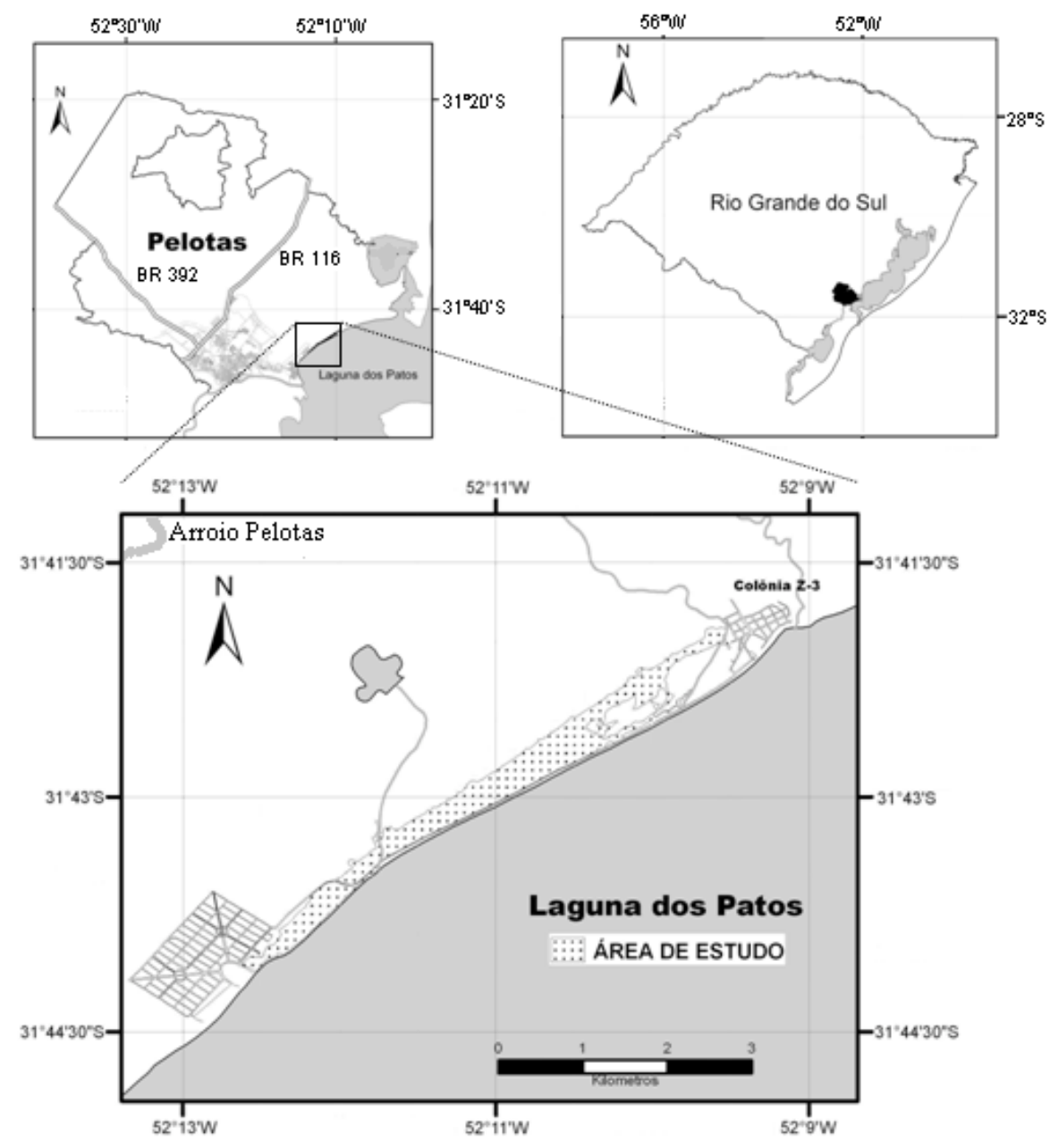

FIGURA 1: Localização da Mata de Restinga da Praia do Totó, município de Pelotas no Rio Grande do Sul, aproximadamente $31^{\circ} 43^{\prime}$ 'S e $52^{\circ} 11^{\prime} \mathrm{W}$, na Mata da Praia do Totó.

FIGURE 1: Location of 'Mata da Praia do Totó', municipality of Pelotas, Rio Grande do Sul state, about approximately $31^{\circ} 43^{\prime} \mathrm{S}$ and $52^{\circ} 11^{\prime} \mathrm{W}$, in Forest of 'Praia do Totó'. 
Os dados deste estudo foram comparados com listas de plantas de 12 trabalhos florísticos e fitossociológicos realizados na Planície Costeira do Rio Grande do Sul e 2 em áreas de Floresta de Encosta, localizadas próximas da área de estudo na borda leste do Escudo Rio-grandense (Tabela 2). A análise da similaridade florística foi feita elaborando um banco de dados da presença e ausência das espécies arbustivo-arbóreas nestas listas. Foram consideradas apenas as plantas determinadas no nível de espécie.

A matriz de similaridade foi obtida utilizando-se para o cálculo o índice de similaridade de Sorensen (MÜELLER-DOMBOIS e ELLEMBERG, 1974). Através deste índice foi elaborado o dendrograma de agrupamento baseado na média de grupo (UPGMA), utilizando o programa Fitopac I (SHEPHERD, 1995) para a classificação das comunidades analisadas.

\section{RESULTADOS E DISCUSSÃO}

A Mata de Restinga da Praia do Totó é coberto por dois tipos vegetacionais distintos, que estão condicionados às condições topográficas do terreno: as matas arenosas, onde os solos possuem drenagem de maior eficiência e as matas turfosas, onde os solos são mal drenados. A mata arenosa coloniza a parte alta da barreira e a mata turfosa, a parte baixa sobre o terraço lagunar e as depressões do terreno. Ambas as formações vegetais são contíguas, como observado em outras matas de restinga na planície costeira do Rio Grande do Sul (PORTO e DILLENBURG, 1986; DORNELES e WAECHTER, 2004a; DORNELES e WAECHTER, 2004b).

A fisionomia das duas comunidades é caracterizada pela diferença na estrutura da mata quanto aos aspectos de área basal e altura dos indivíduos. Na mata arenosa, os espécimes estão mais espaçados e o fuste com diâmetros maiores, principalmente para as espécies Quillaja brasiliensis, Luehea divaricata e Ficus organensis que foram amostrados indivíduos com respectivamente $43 \mathrm{~cm}$, $57 \mathrm{~cm}$ e $98 \mathrm{~cm}$. Na mata turfosa, as árvores possuem menor porte e no geral com área basal reduzida, na maioria até os $20 \mathrm{~cm}$ de diâmetro de fuste. Exceção das espécies Citharexyllum myrianthum, Erythrina cristagalli e Ficus organensis, nos quais foram observados indivíduos com, respectivamente $44 \mathrm{~cm}, 43 \mathrm{~cm}$ e $38 \mathrm{~cm}$. No ambiente turfoso também é frequente encontrar árvores com os troncos ramificados no nível do diâmetro a altura do peito (DAP).

O dossel na mata turfosa varia entre 8 e $9 \mathrm{~m}$ e os indivíduos emergentes alcançam os $11 \mathrm{e}$ $12 \mathrm{~m}$ de altura. Nas áreas clímax da mata arenosa, os indivíduos com caracteres de emergentes chegam a aproximadamente $15 \mathrm{~m}$ e o dossel varia entre 10 $12 \mathrm{~m}$. A diferença de altura entre os dois ambientes, possivelmente seja explicada pela limitação que o substrato da mata turfosa impõe ao desenvolvimento de indivíduos. O grande número de indivíduos de baixa estatura na mata turfosa está relacionado à instabilidade do solo (KINDEL, 2002). O solo conduz o crescimento de raízes superficiais decorrentes da constante superficialidade do lençol freático. A posição do remanescente, fazendo limite com a Laguna dos Patos, expõe a vegetação às forças do vento que, juntamente com as características fitoedáficas do substrato, ampliam a possibilidade de queda dos indivíduos mais altos na mata turfosa.

No levantamento florístico da Mata da Praia do Totó foram inventariadas 65 espécies arbóreas da flora nativa, distribuídas em 51 gêneros pertencentes a 34 famílias botânicas (Tabela 1). Essa riqueza representa $44 \%$ da flora amostrada no município de Pelotas (VENZKE, 2012). A família que apresentou o maior número de espécies foi Myrtaceae, com dez; seguida por Salicaceae com cinco; Euphorbiaceae e Myrsinaceae com quatro; Anarcadiaceae, Moraceae, Sapindaceae e Sapotaceae com três. Outras quatro famílias apresentaram duas espécies cada e com uma espécie foram inventariadas vinte e duas famílias.

A família Myrtaceae tem sido observada com a maior riqueza específica para o componente arbóreo em matas de restinga no Rio Grande do Sul (PORTO e DILLENBURG, 1986; DILLENBURG et al., 1992; ROSSONI, 1993; WAECHTER e JARENKOW, 1998; WAECHTER et al., 2000; MORAES e MONDIN, 2001; KILCA, 2002; KINDEL, 2002; SOBRAL, 2003; DORNELES e WAECHTER, 2004a; DORNELES e WAECHTER, 2004b; De MARCHI, 2005; SCHERER et al., 2005).

O gênero Myrsine (Myrsinaceae) apresentou a maior riqueza, com quatro espécies, seguido de Eugenia (Myrtaceae) com três. Outros nove gêneros foram amostrados com duas espécies cada (Schinus, Cordia, Sebastiania, Ficus, Myrcia, Myrcianthes, Zanthoxylum, Casearia e Chrysophyllum).

A riqueza da comunidade arbórea colonizando os solos da mata turfosa (27 espécies) é menor quando comparado à riqueza da mata arenosa (53 espécies). Esse padrão é conhecido, 
pois as matas de restinga arenosa mostram-se com uma riqueza intermediária de espécies (PORTO e DILLENBURG, 1986; DILLENBURG et al., 1992; ROSSONI, 1993; WAECHTER et al., 2000; MORAES e MONDIN, 2001; DORNELES e
WAECHTER, 2004b; SCHERER et al., 2005) e as matas turfosas são as comunidades arbóreas com a menor riqueza específica na Planície Costeira Gaúcha (WAECHTER e JARENKOW, 1998; DORNELES e WAECHTER, 2004a).

TABELA 1: Relação das famílias, espécies arbóreas e seu respectivo nome popular amostradas em levantamento florístico em mata de restinga arenosa e turfosa na Praia do Totó, Pelotas, Rio Grande do Sul, Brasil. $\mathrm{x}=$ presença; $\mathrm{s} / \mathrm{c}=$ sem coleta; $\mathrm{N}^{\mathrm{o}} \mathrm{PEL}=$ número de tombamento no Herbário da UFPEL.

TABLE 1: List of families, tree species and its popular names sampled in a floristic survey of a sandy and peat coast forest at 'Praia do Totó', Pelotas, Rio Grande do Sul state, Brazil. $\mathrm{x}=$ presence. s/c $=$ without collected. $\mathrm{N}^{\mathrm{o}} \mathrm{PEL}=$ tipping number at UFPEL Herbarium.

\begin{tabular}{|c|c|c|c|c|}
\hline Famílias/Espécie & Nome popular & arenosa & turfosa & $\mathrm{N}^{\circ} \mathrm{PEL}$ \\
\hline \multicolumn{5}{|l|}{ Anacardiaceae } \\
\hline Lithraea brasiliensis Marchand & aroeira-braba & $\mathrm{x}$ & $\mathrm{x}$ & 23.882 \\
\hline Schinus polygamus (Cav.) Cabrera & assobiadeira & $\mathrm{x}$ & & 23.884 \\
\hline Schinus terebinthifolius - Raddi & aroeira-vermelha & $\mathrm{x}$ & & 23.883 \\
\hline \multicolumn{5}{|l|}{ Aquifoliaceae } \\
\hline Ilex dumosa Reissek & caúna & & $\mathrm{x}$ & 23.885 \\
\hline \multicolumn{5}{|l|}{ Arecaceae } \\
\hline Geonoma schottiana Mart. & geonoma, guaricana & & $\mathrm{x}$ & $\mathrm{s} / \mathrm{c}^{\mathrm{B}}$ \\
\hline Syagrus romanzoffiana (Cham.) Glassman & jerivá, coqueiro & $\mathrm{x}$ & $\mathrm{x}$ & $\mathrm{s} / \mathrm{c}$ \\
\hline \multicolumn{5}{|l|}{ Asteraceae } \\
\hline Baccharis longoattenuata An.S.deOliveira & \multicolumn{3}{|c|}{ Boraginaceae } & $36^{\mathrm{A}}$ \\
\hline Cordia americana (L.) Gottschling \& J.E.Mill. & guajuvira & $\mathrm{x}$ & & 24.665 \\
\hline Cordia ecalyculata Vell. & louro-mole & $\mathrm{x}$ & & 24.690 \\
\hline \multicolumn{5}{|l|}{ Cactaceae } \\
\hline $\begin{array}{l}\text { Cereus hildmannianus K.Schum. } \\
\text { Cannabaceae }\end{array}$ & cactus, tuna & $\mathrm{x}$ & & $\mathrm{s} / \mathrm{c}$ \\
\hline $\begin{array}{l}\text { Celtis iguanaea (Jacq.) Sarg. } \\
\text { Cardiopteridaceae }\end{array}$ & taleira & $\mathrm{x}$ & & 23.890 \\
\hline $\begin{array}{l}\text { Citronella gongonha (Mart.) R.A.Howard } \\
\text { Celastraceae }\end{array}$ & Celastraceae & & $\mathrm{x}$ & 23.892 \\
\hline $\begin{array}{l}\text { Maytenus cassineformis Reissek } \\
\text { Ebenaceae }\end{array}$ & coração-de-bugre & $\mathrm{x}$ & & 23.893 \\
\hline \multicolumn{5}{|l|}{ Erythroxylaceae } \\
\hline Erythroxylum argentinum O.E.Schulz & cocão & $\mathrm{x}$ & & 24.668 \\
\hline \multicolumn{5}{|l|}{ Euphorbiaceae } \\
\hline Gymnanthes concolor Spreng. & laranjeira-do-mato & $\mathrm{x}$ & & $27^{\mathrm{A}}$ \\
\hline Sapium glandulosum (L.) Morong & leiteiro & $\mathrm{x}$ & $\mathrm{x}$ & 23.902 \\
\hline Sebastiania brasiliensis Spreng. & branquilho-leiteiro & $\mathrm{x}$ & $\mathrm{x}$ & 23.900 \\
\hline $\begin{array}{l}\text { Sebastiania commersoniana (Baill.) L.B.Sm. \& Downs } \\
\text { Fabaceae }\end{array}$ & branquilho & $\mathrm{x}$ & $\mathrm{x}$ & 23.901 \\
\hline $\begin{array}{l}\text { Erythrina cristagalli } \mathrm{L} . \\
\text { Lamiaceae }\end{array}$ & corticeira-do-banhado & & $\mathrm{x}$ & 23.905 \\
\hline $\begin{array}{l}\text { Vitex megapotamica (Spreng.) Moldenke } \\
\text { Lauraceae }\end{array}$ & tarumã & $\mathrm{x}$ & $\mathrm{x}$ & 23.907 \\
\hline Ocotea pulchella (Ness) Mez & canela-do-brejo & $\mathrm{x}$ & $\mathrm{x}$ & 23.909 \\
\hline
\end{tabular}


TABELA 1: Continuação ...

TABLE 1: Continued ...

\begin{tabular}{|c|c|c|c|c|}
\hline Famílias/Espécie & Nome popular & arenosa & turfosa & $\mathrm{N}^{\mathrm{o}} \mathrm{PEL}$ \\
\hline \multicolumn{5}{|l|}{ Malvaceae } \\
\hline Luehea divaricata Mart. & açoita-cavalo & $\mathrm{x}$ & & $58^{\mathrm{A}}$ \\
\hline \multicolumn{5}{|l|}{ Melastomataceae } \\
\hline Miconia hiemalis A.St.-Hil. \& Naudin ex Naudin & pixirica & $\mathrm{x}$ & & 23.910 \\
\hline \multicolumn{5}{|l|}{ Meliaceae } \\
\hline Trichilia claussenii C.DC. & catiguá & $\mathrm{x}$ & & 24.670 \\
\hline \multicolumn{5}{|l|}{ Moraceae } \\
\hline Ficus enormis (Mart. ex Miq) Mig & figueira-mata-pau & $\mathrm{x}$ & & $\mathrm{s} / \mathrm{c}$ \\
\hline Ficus organensis (Mig.) Miq. & figueira-de-folha-miúda & $\mathrm{x}$ & $\mathrm{x}$ & 23.915 \\
\hline Sorocea bomplandii (Baill.) W.C.Burg, Lanj. \& Boer & cincho & $\mathrm{x}$ & & 24.691 \\
\hline \multicolumn{5}{|l|}{ Myrsinaceae } \\
\hline Myrsine coriacea (Sw.) R.Br. & capororoca & $\mathrm{x}$ & & $45^{\mathrm{A}}$ \\
\hline Myrsine laetevirens (Mez.) Arechav. & capororoca & $\mathrm{x}$ & & $68^{\mathrm{A}}$ \\
\hline Myrsine parvifolia DC. & capororoca & & $\mathrm{x}$ & 23.916 \\
\hline Myrsine umbellata Mart. & capororocão & $\mathrm{x}$ & $\mathrm{x}$ & 23.917 \\
\hline \multicolumn{5}{|l|}{ Myrtaceae } \\
\hline Blepharocalyx salicifolius (Kunth) O.Berg & murta & $\mathrm{x}$ & $\mathrm{x}$ & 23.918 \\
\hline Eugenia myrcianthes Nied. & pessequeiro-da-praia & $\mathrm{x}$ & & 23.919 \\
\hline Eugenia uniflora L. & pitanga & $\mathrm{x}$ & & 23.920 \\
\hline Eugenia uruguayensis Cambess. & guamirim, batinga-vermelha & & $\mathrm{x}$ & 23.921 \\
\hline Myrcia multiflora (Lam.) DC. & cambuí & & $\mathrm{x}$ & 24.666 \\
\hline Myrcia palustris DC. & guamirim-do-brejo & $\mathrm{x}$ & $\mathrm{x}$ & 23.923 \\
\hline Myrcianthes gigantea (D.Legrand) D.Legrand & araçá-do-mato & $\mathrm{x}$ & $\mathrm{x}$ & 23.925 \\
\hline Myrcianthes cisplatensis O.Berg & araçá-do-prata & & $\mathrm{x}$ & $23.924^{\mathrm{B}}$ \\
\hline Myrrhinium atropurpureum Schott & pau-ferro & $\mathrm{x}$ & & 23.926 \\
\hline Psidium cattleianum Sabine & araçá & $\mathrm{x}$ & $\mathrm{x}$ & 23.927 \\
\hline \multicolumn{5}{|l|}{ Nyctaginaceae } \\
\hline Guapira opposita (Vell.) Reitz & maria-mole & $\mathrm{x}$ & $\mathrm{x}$ & 23.928 \\
\hline \multicolumn{5}{|l|}{ Oleaceae } \\
\hline Chionanthus filiformis (Vell.) P.S.Green & azeitona-do-mato & & $\mathrm{x}$ & $24.699^{\mathrm{B}}$ \\
\hline \multicolumn{5}{|l|}{ Polygonaceae } \\
\hline Coccoloba cordata Cham. & pau-de-junta & $\mathrm{x}$ & & 23.929 \\
\hline \multicolumn{5}{|l|}{ Quillajaceae } \\
\hline Quillaja brasiliensis (A.St.-hil. \& Tul.) Mart. & sabão-de-soldado & $\mathrm{x}$ & & 23.930 \\
\hline \multicolumn{5}{|l|}{ Rhamnaceae } \\
\hline Scutia buxifolia Reissek & coronilha & $\mathrm{x}$ & & 23.931 \\
\hline \multicolumn{5}{|l|}{ Rubiaceae } \\
\hline Faramea montevidensis (Cham. \& Schltdl.) DC. & café-do-mato & $\mathrm{x}$ & & $7^{\mathrm{A}}$ \\
\hline Randia ferox (Cham. \& Schltdl.) DC. & limoeiro-do-mato & $\mathrm{x}$ & & 23.936 \\
\hline \multicolumn{5}{|l|}{ Rutaceae } \\
\hline Zanthoxylum fagara (L.) Sarg. & coentrilho & $\mathrm{x}$ & & 24.692 \\
\hline Zanthoxylum rhoifolium Lam. & mamica-de-cadela & $\mathrm{x}$ & & 23.937 \\
\hline \multicolumn{5}{|l|}{ Salicaceae } \\
\hline Banara parviflora (A.Gray) Benth. & cabroé-mirim & $\mathrm{x}$ & $\mathrm{x}$ & 23.939 \\
\hline Casearia decandra Jacq. & guaçatunga-preta & $\mathrm{x}$ & & 23.941 \\
\hline Casearia silvestris $\mathrm{Sw}$. & chá-de-bugre & $\mathrm{x}$ & & 23.942 \\
\hline Salix humboldtiana Willd. & salseiro, salgueiro & & $\mathrm{x}$ & 23.943 \\
\hline Xylosma pseudosalzmannii Sleumer & sucará & $\mathrm{x}$ & & $52^{\mathrm{A}}$ \\
\hline
\end{tabular}


TABELA 1: Continuação ...

TABLE 1: Continued ...

\begin{tabular}{|c|c|c|c|c|}
\hline Famílias/Espécie & Nome popular & arenosa & turfosa & $\mathrm{N}^{\mathrm{o}} \mathrm{PEL}$ \\
\hline \multicolumn{5}{|l|}{ Sapindaceae } \\
\hline Allophylus edulis Niederl. & chal-chal & $\mathrm{x}$ & & 23.994 \\
\hline Cupania vernalis Cambess. & camboatá-vermelho & $\mathrm{x}$ & & 23.995 \\
\hline Dodonaea viscosa Jacq. & vassoura-vermelha & $\mathrm{x}$ & & 23.996 \\
\hline \multicolumn{5}{|l|}{ Sapotaceae } \\
\hline Chrysophyllum gonocarpum (Mart. \& Eichler) Engl. & aguaí-amarelo & $\mathrm{x}$ & & 23.948 \\
\hline Chrysophyllum marginatum (Hook. \& Arn.) Radlk. & aguaí & $\mathrm{x}$ & & 23.940 \\
\hline $\begin{array}{l}\text { Sideroxylon obtusifolium (Roem. \& Schult.) T.D.Penn. } \\
\text { Styracaceae }\end{array}$ & coronilha & $\mathrm{x}$ & & $51^{\mathrm{AB}}$ \\
\hline Styrax leprosus Hook. \& Arn. & carne-de-vaca & $\mathrm{x}$ & & 23.952 \\
\hline Symplocaceae & & & & \\
\hline $\begin{array}{l}\text { Symplocos uniflora (Pohl) Benth. } \\
\text { Verbenaceae }\end{array}$ & sete-sangrias & & $\mathrm{x}$ & 23.953 \\
\hline Citharexyllum myrianthum Cham. & tucaneira, tarumã & & $\mathrm{x}$ & 23.955 \\
\hline
\end{tabular}

Em que: ${ }^{\mathrm{A}}=$ Número de coleta pessoal de Venzke, T.S.; ${ }^{\mathrm{B}}=$ Espécies ameaçadas de extinção

Essas comunidades arbóreas de florestas turfosas/paludosas apresentam baixa diversidade independente da latitude ou região biogeográfica na qual estão inseridas (TORRES et al., 1994; IVANAUSKAS et al., 1997; WAECHTER e JARENKOW, 1998; IMBERT et al., 2000; CATTANIO et al., 2002; KINDEL, 2002; SZTUTMAN e RODRIGUES, 2002).

A baixa riqueza específica dessas matas é atribuída à necessidade das espécies possuírem a capacidade de germinar e crescer em condições de saturação hídrica do solo (DORNELES e WAECHTER, 2004a). A condição de encharcamento constitui um dos principais fatores abióticos selecionadores da ocorrência das espécies vegetais (TORRES et al., 1994) e contribui na seletividade das espécies, que necessitam de adaptabilidade fisiológica para persistir à saturação hídrica (IVANAUSKAS et al., 1997). Os fatores ambientais atuam como barreiras à capacidade de colonização das espécies neste ambiente. Possivelmente pela presença quase permanente de solos encharcados durante o decorrer do ano e que são instáveis e pobres em oxigenação, sendo fatores que limitariam o número de espécies nestes ambientes (PORTO e DILLENBURG, 1986).

Na mata arenosa, juntamente com Sorocea bonplandii e Gymnanthes concolor, são comuns indivíduos da família Rubiaceae habitando o subbosque, principalmente pela presença de arbustos do gênero Psychotria spp. Esse padrão é conhecido para os estudos na região do extremo sul do Brasil em mata de encosta (SOUZA, 2000) e em mata ciliar (KILCA, 2000).

$\mathrm{Na}$ mata turfosa o sub-bosque é singularizado pela presença de uma espécie de Pteridófita (Blechnum sp.), sendo pouco frequente a ocorrência de indivíduos do gênero Psychotria spp. O gênero Blechnum é um dos mais importantes na florística de uma área paludosa de restinga, conforme Athayde-Filho e Windisch (2006) amostraram ao norte da Planície Costeira do Rio Grande do Sul. O estudo de Dorneles e Negrelle (1999), na Planície Costeira na divisa dos estados de Paraná e Santa Catarina, mostra o gênero Blechnum entre as espécies importantes na sinúsia herbácea, destacado em função da alta frequência e cobertura, sendo mais importante em uma das três áreas estudadas.

A fisionomia da mata turfosa é particularizada pelas espécies: Myrcia multiflora, Psidium cattleianum, Ocotea pulchella, Ocotea sp., Myrsine laetevirens, Ilex dumosa, Citharexyllum myrianthum e Syagrus romanzoffiana. Neste grupo de plantas Myrcia multiflora encontrase comumente colonizando o interior da mata. Psidium cattleianum, Ocotea pulchella, Myrsine laetevirens e Ilex dumosa são vegetais componentes do dossel da floresta. As espécies Ficus organensis, Citharexyllum myrianthum e Syagrus romanzoffiana possuem o porte de emergentes. Entre as espécies inventariadas, Chionanthus filiformis, Geonoma schotianna, Ilex dumosa, Citronella gongonha, Erythrina cristagalli, Citharexyllum myrianthum e Myrcia multiflora foram observadas colonizando 
somente o ambiente da mata turfosa. Porém, as plantas Chionanthus filiformis, Ilex dumosa e Citronella gongonha são espécies que também ocorrem em outros tipos vegetacionais na região. Observações indicam a presença de Ilex dumosa e Citronella gongonha habitando ambientes de solos úmidos nas áreas de floresta de encosta (observações pessoais).

As espécies Syagrus romanzoffiana, Myrcia multiflora, Citharexyllum myrianthum, Myrsine laetevirens, Psidium cattleianum e Ocotea pulchella estão entre as espécies mais importantes em estudo de Dorneles e Waechter (2004a) na estrutura de mata turfosa. Essas espécies não predominam no mesmo tipo vegetacional localizado mais ao sul, na Estação Ecológica do Taim (WAECHTER e JARENKOW, 1998). Nesse local as mais importantes na comunidade são Erythrina cristagalli, Ficus organensis, Blepharocalyx salicifolius, Eugenia uruguayensis e Sebastiania brasiliensis. Provavelmente a diferença entre os dois estudos seja porque no Taim ocorre uma comunidade denominada de Seibal. Esta é uma associação bastante pura formada pela Erythrina cristagalli (MARCHIORI, 1997). Esta planta é decídua, heliófita e pioneira em terrenos brejosos ou muito úmidos e com dispersão em formações secundárias, sendo raramente encontrada no interior da mata primária densa (LORENZI, 2002). A espécie possui ampla importância em áreas de banhado, sendo considerada uma espécie-chave nesses ambientes.

$\mathrm{O}$ aspecto fitofisionômico da comunidade da mata arenosa é caracterizado pelos vegetais: Lithraea brasiliensis, Erythroxylum argentinum, Sebastiania brasiliensis, Sebastiania commersoniana, Casearia silvestris, Myrsine umbellata, Zanthoxylum fagara, Chrysophyllum marginatum e Allophylus edulis. Essas espécies são comuns em análises fitossociológicas em matas de restinga arenosas na Planície Costeira do Rio Grande do Sul (DILLENBURG et al., 1992; ROSSONI, 1993; WAECHTER et al., 2000; DORNELES e WAECHTER, 2004b). Aparecem ainda Guapira opposita e Myrrhinium atropurpureum entre as importantes na constituição destas florestas.

Entre os arbustos mais representativos, encontram-se nos ambientes heliófitos Guettarda uruguensis (Rubiaceae) e Daphnopsis racemosa (Thymelaeaceae); e em ambientes esciófitos Trichilia elegans (Meliaceae) e Psychotria carthagenensis (Rubiaceae). Nas bordas da mata arenosa com o ambiente de campo antropizado utilizado para o pastoreio de animais, estão presentes as espécies: Schinus polygamus, Lithraea brasiliensis, Erythroxylum argentinum, Casearia silvestris, Myrsine umbellata, Zanthoxylum fagara $\mathrm{e}$ Chrysophyllum marginatum.

Durante os caminhamentos, as espécies coletadas e/ou observadas raramente nos diferentes ambientes do remanescente foram: Cordia americana, Cordia ecalyculata, Myrrhinium atropurpureum e Chionanthus filiformis, que foram amostradas respectivamente com 2, 2, 1 e 1 indivíduo cada. Cordia americana e Cordia ecalyculata são encontradas em estudos das matas ciliares e de encosta. Myrrhinium atropurpureum foi comum na estrutura de mata arenosa (DORNELES e WAECHTER, 2004b; DILLENBURG et al., 1992).

As plantas Syagrus romanzoffiana, Psidium cattleianum Sebastiania brasiliensis, Sebastiania commersoniana, Ocotea pulchella e Ficus organensis estão distribuídas comumente colonizando as duas formações vegetais, sendo consideradas como espécies com maior valência ecológica na área. Em comunidades de matas de restinga, as populações dessas plantas apresentam diferentes comportamentos.

A palmeira Syagrus romanzoffiana apresenta o primeiro valor de importância na mata turfosa no Parque Nacional da Lagoa do Peixe (DORNELES e WAECHTER, 2004a). Em mata arenosa apresenta baixa densidade (WAECHTER et al., 2000), ou foi ausente em outras áreas (DILLENBURG et al., 1992; ROSSONI, 1993), como também no Parque Nacional da Lagoa do Peixe (DORNELES e WAECHTER, 2004b). Em comunidade ciliar no Rio Piratini (KILCA, 2002) apresenta densidade de 1 indivíduo e no Rio Camaquã participa na estrutura da floresta medianamente (De MARCHI e JARENKOW, 2008).

Psidium cattleianum é importante na estrutura de matas turfosas e arenosa (ROSSONI, 1993; WAECHTER e JARENKOW, 1998; DORNELES e WAECHTER, 2004a). Sebastiania brasiliensis é representativa nos ambientes encharcados da Mata da Praia do Totó, o que é confirmado pela densidade amostrada por Waechter e Jarenkow (1998) na Estação Ecológica do Taim, onde foi a quinta em valor de importância.

O branquilho (Sebastiania commersoniana) é com certeza um vegetal predominante na estrutura das matas arenosas da Planície Costeira. Nessas formações de melhor drenagem, foi a primeira (DILLENBURG et al., 1992), segunda (ROSSONI, 
1993; WAECHTER et al., 2000; DORNELES e WAECHTER, 2004b) e quinta no valor de importância (MORAES e MONDIN, 2001). Em mata turfosa, de solos encharcados permanentemente, a espécie apresenta baixa contribuição na floresta (WAECHTER JARENKOW, 1998; KINDEL, 2002; DORNELES e WAECHTER, 2004a). Contudo, nas matas ciliares de solos encharcados periodicamente é o vegetal de maior valor de importância no Rio Camaquã (De MARCHI e JARENKOW, 2008) ou aparece entre as mais importantes populações nas matas ciliares do Rio Piratini (KINDEL, 2002).

Afigueira Ficus organensis, no remanescente estudado, coloniza as duas comunidades; e em estudo fitossociológico essa espécie possui densidade elevada na mata turfosa do Taim (WAECHTER e JARENKOW, 1998). Porém, quase sempre apresenta baixa densidade, tanto em mata turfosa (DORNELES e WAECHTER, 2004a) como arenosas (WAECHTER et al., 2000; DORNELES e WAECHTER, 2004b). Contudo, pelo elevado diâmetro e altura, se destaca na estrutura desses levantamentos. Esse padrão foi observado no qual a espécie apresenta um porte elevado o que imprime uma importância fisionômica no remanescente.

Emoutras remanescentes de matas de restinga no Município de Pelotas, foi registrada a presença de outros vegetais: Ruprechtia laxiflora (marmeleirodo-mato - Polygonaceae); Mimosa bimucronata (maricá-Fabaceae); Rollinia marítima (araticumAnnonaceae); Jodina rhombifolia (cancorosa-detrês-pontas-Santalaceae) e Gochnatia polymorpha (cambará-Asteraceae). Delas, Jodina rhombifolia e Gochnatia polymorpha estão ameaçadas de extinção (RS, 2003), e foram coletados e observados indivíduos nos capões de mata do Pontal da Barra, Praia do Laranjal.

$\mathrm{Na}$ Mata da Praia do Totó as espécies: Geonoma schotianna (Arecaceae), Myrcianthes cisplatensis (Myrtaceae), Sideroxylon obtusifolium (Sapotaceae) e Chionanthus filiformis (Oleaceae) estão listadas como componentes da flora ameaçados de extinção no Rio Grande do Sul (RS, 2003). Geonoma schotianna é uma espécie de palmeira característica da mata pluvial da encosta atlântica no sul do Brasil (REITZ, 1974). Habita o ambiente de solo brejoso, evento observado em outras áreas de mata de restinga (WAECHTER et al., 2000; KINDEL, 2002; DORNELES e WAECHTER, 2004a). A espécie é componente do sub-bosque da mata, conforme Dorneles e Waechter (2004a) observaram no Parque Nacional da Lagoa do Peixe.
Chionanthus filiformis foi coletada habitando o ambiente da mata turfosa e constituindo o dossel. Souza (1999) cita a espécie na localidade denominada de "Cerro das Almas" (31 $466^{\circ} \mathrm{S}$, $52^{\circ} 35^{\prime} \mathrm{W}$ ), situado na Serra dos Tapes (encosta do Escudo Rio-grandense) e a cerca de $30 \mathrm{~km} \mathrm{da}$ área de estudo. Sideroxylon obtusifolium habita os ambientes de mata arenosa, principalmente nos locais dominados pela matriz de campo, entremeado de capões arbóreos.

O remanescente abriga uma espécie de Pteridófita e uma de Gimnosperma ameaçada de extinção (RS, 2002). Dicksonia sellowiana (Dicksoniaceae) é vegetal arborescente com distribuição rara e que habita o sub-bosque da mata turfosa. Ephedra tweediana (Ephedraceae) possui caráter arbustivo-apoiante e é encontrada em ambientes de luz difusa e de menor umidade no solo.

$\mathrm{Na}$ análise da similaridade, o número de espécies amostradas foi de 198, distribuídas nos 16 levantamentos comparados (Tabela 2). Esse total representa cerca de $38 \%$ da flora arbórea inventariada no estado do Rio Grande do Sul (REITZ et al., 1983; SOBRAL et al., 2006). Desse total, 64 $(32,3 \%)$ foram registradas em apenas uma das áreas comparadas floristicamente.

As espécies de maior frequência perfazem 30 espécies $(15,1 \%)$ e estão listadas na Tabela 3. Entre estas plantas mais comuns da unidade fitogeográfica da Planície Costeira, a espécie Coussapoa microcarpa não foi amostrada na Mata da Praia do Totó. Porém, as plantas Chionanthus filiformis, Miconia hiemalis e Baccharis longoattenuata são novas citações para a Planície Costeira no Rio Grande do Sul.

Apesar dos estudos usados para as comparações terem usado metodologias diferentes, $\mathrm{o}$ conjunto de espécies listadas na Tabela 3, demonstra ampla distribuição geográfica no território. São plantas comumente encontradas colonizando a região geológica da Planície Costeira no Rio Grande do Sul, sendo floristicamente indicadas para usar em projetos de reflorestamentos de essências nativas na unidade fitogeográfica da Planície Costeira deste estado.

A análise de agrupamento da biodiversidade das 16 listas comparadas revelou a formação de grupos com níveis elevados de similaridade. Níveis elevados de similaridade, acima de $25 \%$ (MÜELLER-DOMBOIS e ELLENBERG, 1974), geralmente são encontrados quando se considera o mesmo tipo de unidade vegetacional e proximidade espacial (RODRIGUES e NAVE, 2000). 
TABELA 2: Lista das áreas de estudos realizados em formações florestais da Planície Costeira do Rio Grande do Sul e utilizadas para as análises de similaridade florística. Autor(es), metodologia ( $\mathrm{DAP}=$ diâmetro a altura do peito, $\mathrm{n}=$ número de pontos amostrais), riqueza espécies $(\mathrm{Ne})$, gêneros $(\mathrm{G})$, famílias botânicas $(\mathrm{F})$, índice (ISS \%), tipologia florestal (are = arenosa; tur = turfosa) e código do estudo $\left(\mathrm{N}^{\circ}\right)$.

TABLE 2: List of the areas of study in forest commnunities of Rio Grande do Sul coastal plain used for floristic analysis similarities. Author(s), methodology - DBH (diameter at breast height), $\mathrm{n}=$ number of sampling points), species richness $(\mathrm{Ns})$, genera $(\mathrm{G})$, botanic family (F), ISS index $\%$, forest type (are = sandy; tur $=$ swamp), and code study $\left(\mathrm{N}^{\circ}\right)$.

\begin{tabular}{|c|c|c|c|c|c|c|c|c|}
\hline $\begin{array}{l}\text { Comunidade } \\
\text { vegetal }\end{array}$ & Autor/data & $\begin{array}{l}\text { Método de amostragem } \\
\text { (DAP em } \mathrm{cm} \text { ) }\end{array}$ & $\mathrm{Ne}$ & G & $\mathrm{F}$ & $\begin{array}{l}\text { ISS } \\
\text { are }\end{array}$ & $\begin{array}{l}\text { ISS } \\
\text { tur }\end{array}$ & $\mathrm{N}^{\mathrm{o}}$ \\
\hline Mata ciliar & Kilca, $(2002)^{\mathrm{A}}$ & parcelas; 1 ha; DAP $\geq 5$ & 76 & 56 & 32 & 67 & 29 & 10 \\
\hline Flor. de encosta & Souza $(2001)^{A}$ & parcelas; 1 ha; DAP $\geq 5$ & 74 & 57 & 35 & 55 & 33 & 12 \\
\hline Flor de encosta & Jurinitz; Jarenkow (2003) & parcelas; 1ha; DAP $\geq 5$ & 69 & 55 & 34 & 42 & 25 & 13 \\
\hline Mata ciliar & De Marchi $(2005)^{\mathrm{A}}$ & parcelas; 1 ha; DAP $\geq 5$ & 68 & 55 & 29 & 49 & 27 & 8 \\
\hline Mata arenosa & Este estudo & florística; DAP $\geq 5$; altura $\geq 4 \mathrm{~m}$. & 53 & 42 & 28 & - & 38 & 1 \\
\hline Mata arenosa & Waechter et al. $(2000)^{\mathrm{A}}$ & quadrantes; $(n=60)$ DAP $\geq 10$ & 52 & 44 & 26 & 58 & 29 & 4 \\
\hline Mata arenosa & Rossoni (1993) & quadrantes; $(n=100)$ DAP $\geq 5$ & 47 & 42 & 26 & 45 & 35 & 9 \\
\hline Mata turfosa & Kindel (2002) & parcelas; 0,1 ha; DAP $\geq 2,5$ & 44 & 36 & 20 & 18 & 24 & 14 \\
\hline Arenosa e turfosa & Porto; Dillenburg (1986) & florística & 41 & 36 & 28 & 57 & 39 & 16 \\
\hline Mata turfosa & Este estudo & florística; DAP $\geq 5$; altura $\geq 4 \mathrm{~m}$. & 27 & 20 & 16 & 38 & - & 2 \\
\hline Mata arenosa & Dorneles; Waechter (2004) $\mathrm{b}^{\mathrm{A}}$ & quadrantes; $(\mathrm{n}=60) \mathrm{DAP} \geq 5$ & 27 & 25 & 19 & 48 & 21 & 7 \\
\hline Mata arenosa & Moraes; Mondin $(2001)^{A}$ & quadrantes; $(\mathrm{n}=30) \mathrm{DAP} \geq 5$ & 31 & 25 & 20 & 48 & 30 & 15 \\
\hline Mata arenosa & Scherer et al. (2005) & parcelas; $1,02 \mathrm{ha} ; \mathrm{DAP} \geq 5$ & 31 & 26 & 20 & 44 & 33 & 11 \\
\hline Mata arenosa & Dillenburg et al. $(1992)^{\mathrm{A}}$ & quadrantes; $(\mathrm{n}=45) \mathrm{DAP} \geq 5$ & 21 & 21 & 18 & 44 & 32 & 5 \\
\hline Mata turfosa & Dorneles; Waechter (2004)a & quadrantes; $(n=60)$ DAP $\geq 5$ & 21 & 18 & 14 & 23 & 50 & 6 \\
\hline Mata turfosa & Waechter; Jarenkow $(1998)^{\mathrm{A}}$ & quadrantes; $(\mathrm{n}=30)$ DAP $\geq 10$ & 19 & 18 & 14 & 41 & 54 & 3 \\
\hline
\end{tabular}

Em que: ${ }^{\mathrm{A}}=$ Estudos fitossociológicos que incluíram espécies observadas fora do método de amostragem.

No dendrograma da análise de agrupamento formaram-se três grandes grupos (Figura 2). O grupo I é formado pelos trechos de estudos em matas arenosas distribuídos pela Planície Costeira $(4,5,7,9,11,15,16)$. O grupo II é constituído pelas florestas de encosta (12 e 13), matas ciliares (8 e 10) e a mata arenosa da Mata da Praia do Totó (1). O grupo III é composto pelas áreas de mata turfosa de encharcamento periódico no solo $(2,3,6,14)$.

É interessante ressaltar que a análise de similaridade mostra a clara distinção florística entre as matas arenosas e turfosas, concordando com as distinções na composição da flora existente nestas florestas numa mesma localidade, como observado por Dorneles e Waechter (2004a); Dorneles e Waechter (2004b).

$\mathrm{O}$ estudo de menor similaridade florística foi com floresta turfosa localizada no Município de Torres, RS (KINDEL, 2002), mesmo quando comparada com florestas paludosas na Planície Costeira, evidenciando que compartilham poucas espécies em comum.

A biodiversidade exclusiva no estudo no norte da Planície Costeira, como a presença de Euterpe edulis com a maior densidade, pode ser explicada pela localização da área, inserida sobre a influência da extremidade sul da distribuição da Mata Atlântica strictu sensu. Essa região é denominada de "Portal de Torres", expressão de P. Balduíno Rambo (RAMBO, 1950), formando um estreito corredor ocupando a planície quaternária da costa e a encosta da Serra Geral, até uma altitude de 700 a 900 m, sendo um limite de distribuição de espécies tropicais (REITZ et al., 1983). 
TABELA 3: Relação das espécies mais comuns em levantamentos nas comunidades florestais da Planície Costeira do Rio Grande do Sul. $\mathrm{N}=$ número de amostras.

TABLE 3: List of the most common species in the surveys of forests communities of Rio Grande do Sul Coastal Plain. N = number of samples.

\begin{tabular}{lll}
\hline Espécie & Família & $\mathrm{N}$ \\
\hline Ficus organensis & Moraceae & 16 \\
Sebastiania commersoniana & Euphorbiaceae & 13 \\
Vitex megapotamica & Lamiaceae & 13 \\
Guapira opposita & Nyctaginaceae & 13 \\
Casearia sylvestris & Salicaceae & 13 \\
Syagrus romanzoffiana & Arecaceae & 12 \\
Myrsine umbellata & Myrsinaceae & 12 \\
Allophylus edulis & Sapindaceae & 12 \\
Chrysophyllum marginatum & Sapotaceae & 12 \\
Lithraea brasiliensis & Anacardiaceae & 11 \\
Erythroxylum argentinum & Erythroxylaceae & 11 \\
Ocotea pulchella & Lauraceae & 11 \\
Casearia decandra & Salicaceae & 11 \\
Blepharocalyx salicifolius & Myrtaceae & 10 \\
Myrcia palustris & Myrtaceae & 10 \\
Zanthoxylum fagara & Rutaceae & 10 \\
Eugenia uruguayensis & Myrtaceae & 9 \\
Psidium cattleianum & Myrtaceae & 9 \\
Sideroxylon obtusifolium & Sapotaceae & 9 \\
Diospyros inconstans & Ebenaceae & 8 \\
Eugenia uniflora & Myrtaceae & 8 \\
Myrrhinium atropurpureum & Myrtaceae & 8 \\
Coussapoa microcarpa & Urticaceae & 8 \\
Cereus hildmannianus & Cactaceae & 7 \\
Celtis iguanaea & Cannabaceae & 7 \\
Sapium glandulosum & Euphorbiaceae & 7 \\
Sebastiania brasiliensis & Euphorbiaceae & 7 \\
Sorocea bomplandii & Moraceae & 7 \\
Randia ferox & Rubiaceae & 7 \\
\hline & Sapotaceae & 7 \\
\hline
\end{tabular}

Até o momento os estudos florísticos e fitossociológicos desenvolvidos na unidade fitogeográfica da Planície Costeira Rio-grandense determinam a maior diversidade de espécies arbóreas nas comunidades ciliares (KILCA, 2002; De MARCHI, 2005). A riqueza elevada nestas é atribuída à presença de conectividade direta das matas ciliares com florestas mais diversas situadas à montante destas formações nas áreas de encosta (SOUZA, 2001; JURINITZ e JARENKOW, 2003).

A relação florística entre as matas ciliares e de encosta é evidente quando se observa o grupo II no dendrograma da Figura 2, que identifica maior semelhança entre florestas ciliares, de encosta e a arenosa da Mata da Praia do Totó. A presença da Mata Arenosa agrupada junto a florestas de maior diversidade pode ser explicada pela proximidade geográfica entre os estudos e também que as matas ciliares formam corredores de migração das espécies. Possivelmente as matas ciliares do Arroio Pelotas (Arroio é sinônimo de rio de pequeno e médio porte), cujo leito principal encontra-se aproximadamente a $4 \mathrm{~km}$ de distância da área de estudo, formariam um corredor para a dispersão das espécies em tempos passados. Assim, favorecendo a dispersão e a expansão da área geográfica de espécies das florestas interioranas para as areias da Planície Costeira (RAMBO, 1956; WAECHTER, 1990).

A alta riqueza específica da Mata da Praia do Totó e a sua relação florística com matas ciliares e de encosta, se deve, provavelmente, à localização geográfica do remanescente, sendo influenciado pela contribuição do contingente migratório da Serra dos Tapes. Desde modo a Mata da Praia do Totó possui uma diversidade elevada de espécies para formações arbóreas de restinga no Rio Grande do Sul (PORTO e DILLENBURG, 1986; WAECHTER Y JARENKOW, 1998; WAECHTER et al., 2000; DORNELES e WAECHTER, 2004a; DORNELES e WAECHTER 2004b).

Além da ligação com matas mais diversas (ciliares e encosta), a heterogeneidade ambiental do lugar é agente influenciador da elevada biodiversidade arbórea. $\mathrm{O}$ remanescente abrange ambientes de matas arenosas e turfosas, estes formados por ambientes de borda, clareira, interior e em diferentes estágios de regeneração. Desde modo, são relevantes outros estudos que permitam conhecer as suas características para incentivar a conservação deste local, visando futuras medidas de proteção e uso sustentável do remanescente. 


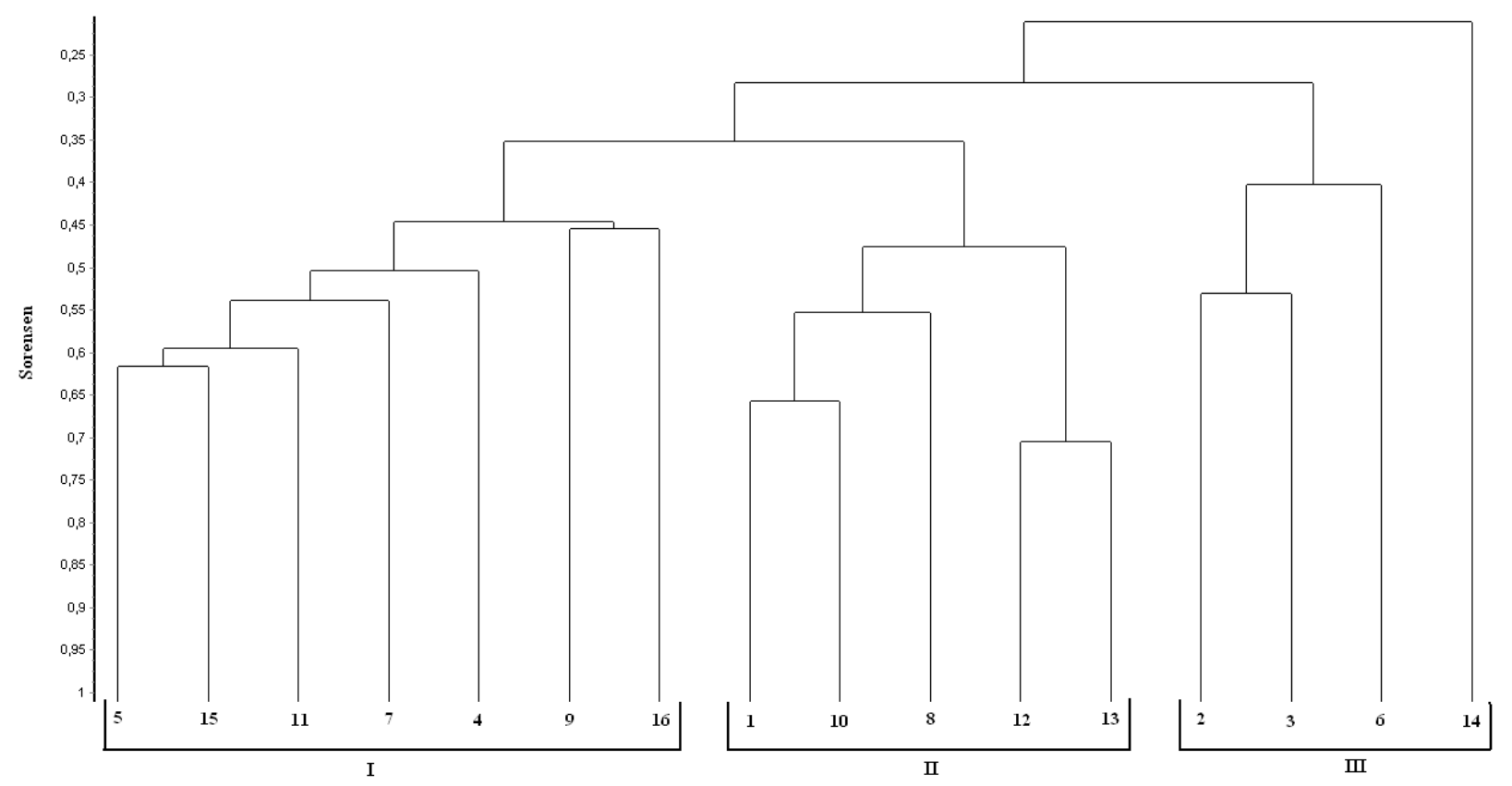

FIGURA 2: Dendrograma da análise de agrupamento, utilizando-se o índice de similaridade de Sorensen, para áreas de comunidades florestais de restinga na Planície Costeira do Rio Grande do Sul.

FIGURE 2: Dendogram of cluster analysis using Sorensen similarity index for forest communities areas of 'Restinga' in Rio Grande do Sul coastal plain.

\section{CONCLUSÕES}

Conforme os resultados obtidos, conclui-se com as observações a seguir:

a) A área de estudo concentra uma biodiversidade elevada de espécies arbóreas nativas para matas de restinga na Planície Costeira do Rio Grande do Sul; e por estar localizada em uma paisagem de matriz campestre, é importante local para a conservação da biodiversidade e como banco de germoplasma de árvores, visando futuros projetos de recuperação ambiental nesta região;

b) A riqueza de espécies entre as duas formações florestais é diferenciada, sendo que a mata arenosa contribui com maior número de espécies para a riqueza da Mata da Praia do Totó;

c) A mata arenosa é floristicamente semelhante com as comunidades florestais ciliares e de encosta, e a mata turfosa é relacionada botanicamente com outras florestas localizadas em áreas de saturação hídrica permanente do solo na Planície Costeira.

\section{AGRADECIMENTO}

Especiais agradecimentos ao Laboratório de Geoprocessamento da UCPel; ao estagiário Jackes Douglas Manke dos Santos pela análise espacial da área de estudo; ao colega e ecólogo Gabriel Kaster Herter pela ajuda esporádica nas atividades de campo e à família do primeiro autor pelo apoio para a realização das atividades do trabalho.

\section{REFERÊNCIAS BIBLIOGRÁFICAS}

APG III. An update of the Angiosperm Phylogeny Group classification for the orders and families of flowering plants: The angiosperm pylogeny group III. Botanical Journal of the Linnean Society, London, v. 161, p. 105-121. 2009.

ARAÚJO, D. S. D.; LACERDA, L. D. A natureza das restingas. Ciência Hoje, v. 6, n. 33, p. 42-48, jul. 1987.

ASSIS, A. M.; THOMAZ, L. D.; PEREIRA, O. J. Florística de um trecho de floresta de restinga no município de Guarapari, Espírito Santo, Brasil. Acta Botanica Brasilica, São Paulo, v. 18, n.1, p. 191-201, jan./mar. 2004.

ATHAYDE-FILHO, F. P.; WINDISCH, P. G. Florística e aspectos ecológicos das pteridófitas em uma floresta de Restinga no estado do Rio Grande do Sul, Brasil. Iheringia, Série Botânica, Porto Alegre, v. 61, n. 1-2, p. 63-71, jan./dez. 2006.

CATTANIO, J. H.; ANDERSON, A. B.; CARVALHO, M. S. Floristic composition and topographic variation in a tidal floodplain forest 
in the Amazon Estuary. Revista Brasileira de Botânica, v. 25, n. 4, p. 419-430, dez. 2002. De MARCHI, T. C. Estudo do componente arbóreo de mata ribeirinha no Rio Camaquã, Cristal, RS. 2005. 50 f. Dissertação (Mestrado em Botânica) - Universidade Federal do Rio Grande do Sul, Porto Alegre, 2005.

De MARCHI, T. C.; JARENKOW, J. A. Estrutura do componente arbóreo de mata ribeirinha no rio Camaquã, Município de Cristal, Rio Grande do Sul, Brasil. Iheringia: Série Botânica, v. 63, n. 2, p. 241248, jul./dez. 2008.

DILLENBURG, L. R.; WAECHTER, J. L.; PORTO, M. L. Species composition and structure of a sandy coastal plain forest in northem Rio Grande do Sul, Brazil. In: SEELIGER, U. (ed.) Coastal plant communities of Latin America. San Diego: Academic Press, 1992, p. 349-366.

DORNELES, L. P. P; NEGRELLE, R. R. B. Composição florística e estrutura do compartimento herbáceo de um estágio sucessional avançado de Floresta Atlântica, no sul do Brasil. Biotemas, v. 12, n. 2, p. 7-30, nov. 1999.

DORNELES, L. P. P; WAECHTER J. L. Estrutura do componente arbóreo da floresta arenosa de restinga do Parque Nacional da Lagoa do Peixe, Rio Grande do Sul. Hoehnea, v. 31, n. 1, p. 61-71. 2004b.

DORNELES, L. P. P; WAECHTER J. L. Fitossociologia do componente arbóreo na floresta turfosa do Parque Nacional da Lagoa do Peixe, Rio Grande do Sul, Brasil. Acta Botanica Brasilica, São Paulo, v. 18, n. 4, p. 815-824, out./dez. 2004a. FIDALGO, O.; BONONI, V. L. R. Técnicas de coleta, preservação e herborização de material botânico. São Paulo: Instituto de Botânica, 1984. $60 \mathrm{p}$.

IMBERT, D. et al. Floristic and structure of the Pterocarpus officinalis swamp forest in Guadeloupe, Lesser Antilles. Journal of Tropical Ecology, Cambridge, v. 16, p. 55-68. 2000.

IVANAUSKAS, N. M.; RODRIGUES, R. R.; NAVE, A. G. Aspectos ecológicos de um trecho de Floresta de brejo em Itatinga, SP: florística, fitossociologia e seletividade de espécies. Revista Brasileira de Botânica, São Paulo, v. 20, n. 2, p. 139-153, dez. 1997.

JURINITZ, C. F.; JARENKOW, J. A. Estrutura do componente arbóreo de uma floresta estacional na Serra do Sudeste, Rio Grande do Sul, Brasil. Revista Brasileira de Botânica, São Paulo, v. 26, n. 4, p. 475-487, out./dez. 2003.
KILCA, R. V. Alguns aspectos florísticos e estruturais de uma floresta de galeria no sul da Planície Costeira do Rio Grande do Sul. 2002. 80 f. Monografia (Graduação em Ciências Biológicas) - Universidade Federal de Pelotas, Pelotas, 2002. KINDEL,A. Diversidade e estratégias de dispersão de plantas vasculares da floresta paludosa do Faxinal, Torres, RS. 2002. 102 f. Tese (Doutorado em Botânica) - Universidade Federal do Rio Grande do Sul, Porto Alegre, 2002.

LORENZI, H. Árvores brasileiras: Manual de identificação e cultivo de plantas arbóreas nativas do Brasil. 4. ed. Nova Odessa: Plantarum, 2002. $368 \mathrm{p}$.

MARCHIORI, J. N. C. Dendrologia das Angiospermas: Leguminosas. Santa Maria: Ed. UFSM, 1997. 200 p.

MORAES, D.; MONDIN, C. A. Florística e fitossociológia do estrato arbóreo em mata arenosa no balneário do Quintão, Palmares do Sul, Rio Grande do Sul. Pesquisas, Botânica, São Leopoldo, n. 51, p. 87-100. 2001.

MUELLER-DOMBOIS, D.; ELLENBERG, $\mathrm{H}$. Aims and methods of vegetation ecology. New York: John Wiley \& Sons, 1974. 363 p.

OLIVEIRA, A. A. B.; RIBEIRO A. G. Climatologia. In: BRASIL. Levantamento de recursos naturais. Rio de Janeiro: SEPLAN - IBGE, 1986, p. 633-772. PELOTAS - Prefeitura Municipal de Pelotas. Lei $n^{\circ} 4336$ de 18 de dezembro de 1998. Declara de valor paisagístico e ecológico a Mata do Totó, localizada no Balneário do Laranjal e Barro Duro. Site: http://www.pelotas.rs.gov.br/interesse legislacao/leis/antigo/L1998/Lei_n_4.336.pdf. Consulta: 24 de novembro de 2006.

PORTO, M. L.; DILLENBURG, L. R. Fisionomia e composição florística de uma mata de restinga da Estação Ecológica do Taím, Brasil. Ciência e Cultura, Campinas, v. 38, n. 7, p. 1228-1236, jul. 1986.

RAMBO, B. A fisionomia do Rio Grande do Sul. 2. ed. Porto Alegre, Livraria Selbach, 1956. 473 p.

RAMBO, B. A Porta de Torres. Anais Botânicos do Herbário Barbosa Rodrigues. Itajaí, v. 2, p. 125136. 1950.

REITZ, R. Palmeiras. In: REITZ, P.R. (ed.). Flora Ilustrada Catarinense. 1974.

REITZ, R., KLEIN, R. M., REIS, A. Projeto Madeira do Rio Grande do Sul. Sellowia, Itajaí, n. 34-35, p. 1-525. 1983.

RIO GRANDE DO SUL. Decreto Estadual $\mathbf{n}^{0}$ 42.099 de $1 \circ$ de janeiro de 2003. Lista final das 
espécies da flora ameaçadas. Site: http://www.fzb. rs.gov.br/downloads/flora_ameaçada.pdf. Consulta: 16 de agosto de 2007.

RIZZINI, C.T. Tratado de fitogeografia do Brasil. Rio de Janeiro, Âmbito Cultural, 1997. 747 p.

RODRIGUES, R. R.; NAVE, A. G. Heterogeneidade florística das matas ciliares. In: RODRIGUES, R. R.; LEITÃO-Filho, H. F. Matas ciliares: conservação e recuperação. São Paulo: Edusp/Fapesp, 2000. p. 45-71.

ROSSONI, M. G. Estudo fitossociológico da mata de restinga, no balneário de Rondinha Velha, Arroio do Sal, RS. 1993. 73 f. Dissertação (Mestrado em Botânica) - Universidade Federal do Rio Grande do Sul, Porto Alegre, 1993.

SCHERER,A.; MARASCHIN-SILVA,; BAPTISTA, L. R. M. Florística e estrutura do componente arbóreo de matas de restinga arenosa no Parque Estadual de Itapuã, RS, Brasil. Acta Botanica Brasilica, São Paulo, v. 19, n. 4, p. 717-726, out./dez. 2005.

SHEPHERD, G. J. Fitopac 1: manual o usuário. Campinas, Unicamp, 1995. 17 p.

SOBRAL, M. A família das Myrtaceae no Rio Grande do Sul. São Leopoldo: Ed. Unisinos, 2003. $215 \mathrm{p}$.

SOBRAL, M. et al. Flora arbórea e arborescente do Rio Grande do Sul. São Carlos: Novo Ambiente, 2006. $350 \mathrm{p}$.

SOUZA, C. A. Estrutura do componente arbóreo de floresta pluvial subtropical na Serra dos Tapes, sul do Rio Grande do Sul. 2001. 54 f. Dissertação (Mestrado em Botânica) - Universidade Federal do Rio Grande do Sul, Porto Alegre, 2001.

STRECK, E.V. et al. Solos do Rio Grande do Sul. 2. ed. Porto Alegre: EMATER/RS-ASCAR, 2008. $222 \mathrm{p}$.

SZTUTMAN, M.; RODRIGUES, R. R. O mosaico vegetacional numa área de floresta contínua da planície litorânea, Parque Estadual da Campina do Encantado, Pariquera, Açu, SP. Revista Brasileira de Botânica, São Paulo, v. 25, n. 2, p. 61-176, jun.
2002.

TEIXEIRA, M. B. et al. Vegetação. In: BRASIL: Levantamento de recursos naturais. Rio de Janeiro: IBGE, 1986. p. 541-632.

TOMAZZELLI, L. J.; DILLENBURG, S. R.; VILLWOCK, J. A. Late quaternary geological history of Rio Grande do Sul coastal plain, southern Brasil. Revista Brasileira de Geociências, v. 30, n.3, p. 474-476, 2000.

TORRES, R. B., MATTHES, L.A. F.; RODRIGUES, R. R. Florística e estrutura do componente arbóreo de uma mata de brejo em Campinas, SP. Revista. Brasileira de Botânica, v.17, n. 2, p. 189-194, dez. 1994.

VENZKE, T. S. Florística de comunidades arbóreas no Município de Pelotas, Rio Grande do Sul, extremo sul do Brasil. Rodriguesia, Rio de Janeiro, v. 63, n. 3, p. 571-578, jul. 2012.

VIEIRA, E. F.; RANGEL, S. R. S. Planície Costeira do Rio Grande do Sul: geografia física, vegetação e dinâmica sócio-demográfica. Porto Alegre: Sagra, 1988. $256 \mathrm{p}$.

WAECHTER, J. L. Aspectos ecológicos da vegetação de restinga no Rio Grande do Sul, Brasil. Comunicações do Museu de Ciências da PUCRS: Botânica, Porto Alegre, v. 33, p. 49-68. 1985.

WAECHTER, J. L. Comunidades vegetais das restingas do Rio Grande do Sul. In: SIMPÓSIO DE ECOSSISTEMAS DA COSTA SUL E SUDESTE BRASILEIRA, 2., 1990, São Paulo. Anais... Águas de Lindóia: São Paulo, 1990, p. 228-248.

WAECHTER, J. L. et al. Estrutura do componente arbóreo em uma floresta subtropical de planície costeira interna. In: SIMPÓSIO DE ECOSSISTEMAS BRASILEIROS, 5., 2000, Vitória. Anais... São Paulo: ACIESP, 2000, p. 92112.

WAECHTER, J. L.; JARENKOW, J. A. Composição e estrutura do componente arbóreo nas matas turfosas do Taim, Rio Grande do Sul. Biotemas, Florianópolis, v. 11, n. 1, p. 45-69, mai. 1998. 